\title{
Preparation and Characterization of Ramie-Glass Fiber Reinforced Polymer Matrix Hybrid Composites
}

\author{
Daiane Romanzini* ${ }^{\mathrm{a}}$, Heitor Luiz Ornaghi Junior ${ }^{\mathrm{b}}$, Sandro Campos Amico ${ }^{\mathrm{b}}$, Ademir José Zattera \\ aLaboratório de Polímeros, Universidade de Caxias do Sul - UCS, Rua Francisco Getúlio Vargas, \\ 1130, CEP 95070-560, Caxias do Sul, RS, Brazil \\ 'Programa de Pós-graduação em Engenharia de Minas, Metalúrgica e de Materiais, \\ Universidade Federal do Rio Grande do Sul-UFRGS, Av. Bento Gonçalves, \\ 9500, CEP 91501-970, Porto Alegre, RS, Brazil
}

Received: November 25, 2011; Revised: February 26, 2012

\begin{abstract}
The use of ramie fibers as reinforcement in hybrid composites is justified considering their satisfactory mechanical properties if compared with other natural fibers. This study aims to verify changes in chemical composition and thermal stability of the ramie fibers after washing with distilled water. One additional goal is to study glass fiber and washed ramie fiber composites focusing on the effect of varying both the fiber length $(25,35,45$ and $55 \mathrm{~mm})$ and the fiber composition. The overall fiber loading was maintained constant (21 vol.\%). Based on the results obtained, the washed ramie fiber may be considered as an alternative for the production of these composites. The higher flexural strength presented being observed for $45 \mathrm{~mm}$ fiber length composite, although this difference is not significant for lower glass fiber volume fractions: $(0: 100)$ and $(25: 75)$. Also, by increasing the relative volume fraction of glass fiber until an upper limit of $75 \%$, higher flexural and impact properties were obtained.
\end{abstract}

Keywords: natural fiber, glass fiber, hybrid composite, ramie

\section{Introduction}

The use of natural fibers as reinforcement in polymeric composites has increased due to their low cost, biodegradability and low specific weight that may even yield higher specific strength and stiffness than glass fiber. Also, production of fibers requires a small amount of energy at low $\mathrm{CO}_{2}$ emission and no abrasion during processing. A wide range of fibers can be applied as reinforcement, including cotton, flax, hemp, ramie, sisal, jute, banana, bamboo, curaua and buriti ${ }^{1-7}$.

Actually, ramie textile applications have been replaced by synthetic fibers, mainly in clothes ${ }^{2}$. So, the motivation of this work is to study ramie fiber as composite reinforcement, with the concern to, in the future, maintain the culture of the fiber in the country. Also, to attend the urgent need to develop environment-friendly materials, this study focused on to improve the fiber-matrix interaction without chemical treatments (washed ramie fiber) and to prepare the composites by the resin transfer molding (RTM) technique. RTM is used in the automobilist industry and have some advantages against conventional techniques, e.g. low capital investment, void content reduction, low cycle times, better process control with consequently waste reduction ${ }^{6}$.

China and the Philippines are the largest producers of ramie fiber. Nowadays, Brazil is the third global producer of ramie, a plant of the Urticaceae family, derived from the bast of Boehmeria nivea and Boehmeria tenacissima, the fibers of which are long, ranging between 150 and $200 \mathrm{~mm}^{[8]}$. The chemical composition of the ramie fiber is: cellulose (68.6-76.2 wt. (\%)); hemicellulose (13.1-16.7 wt. (\%));

*e-mail: ajzattera@ucs.com.br lignin (0.6-0.7 wt. (\%)); pectin (1.9 wt. (\%)); wax $(0.3$ wt. $(\%))$; moisture content $(7.5-17 \text { wt. }(\%))^{9}$. In relation to mechanical properties, Margem et al. ${ }^{2}$ reported that the exceptional tensile strength of ramie fiber (in comparison with other natural fibers) has motivated researches on its application in polymer composites.

There are some disadvantages in the use of the natural fibers in polymeric composites, including high moisture absorption, non uniformity and poor mechanical properties. The major disadvantage is the polar and hydrophilic nature of lignocellulosic fibers and the non-polar characteristics of thermosetting resins. ${ }^{7}$ This results in a poor interphase between fiber and matrix. To improve fiber-matrix interaction, the fiber surface can be treated (e.g. alkali treatment, isocyanate treatment, peroxide treatment, vinyl grafting, bleaching, acetylation, and treatment with coupling agents), but the cost and complexity of these treatments can make it rather expensive ${ }^{10}$.

Spinacé et al. ${ }^{11}$ submitted the curaua fiber to four different treatments: a) pristine curaua; b) curaua washed with water; c) curaua treated with sodium hypochlorite and d) curaua treated with cold oxygen plasma. The washed fibers showed lower moisture content values and an increasing in the crystallinity and surface roughness. For fibers treated with sodium hypochlorite, the behavior is very similar, while for fibers treated with cold oxygen plasma a decreasing of crystallinity was observed. Thus, to remove impurities and improve the fiber-matrix interaction without chemical treatments, fibers washed with water is a viable alternative. 
The properties of natural fiber composites can be enhanced via hybridization with synthetic fibers (e.g. glass fiber), aiming to improve among other properties stiffness, strength and moisture resistance of the composites. The possibility of mixing different types of reinforcement is interesting: the natural reinforcement is recyclable and it allows that tailor made mechanical properties to be obtained. Thus, a balance between environmental impact and performance can be achieved ${ }^{11-13}$.

Jawaid and Khalil ${ }^{13}$ cited recent relevant studies about polymer hybrid composites, and a limited number of studies related to hybridization of ramie with another natural or synthetic fiber. For instance, Paiva Júnior et al. ${ }^{14}$ studied polyester/hybrid ramie-cotton fabric composites, molded by compression. They concluded that ramie fibers have a great potential as fiber reinforcement in resin matrix composites materials, which showed an increase on the tensile strength over the neat resin of up to $338 \%$.

This work aims to study changes in chemical composition and thermal stability of ramie fibers by washing them with distilled water. An additional goal is to study the incorporation of glass fiber and washed ramie fiber into a polyester matrix focusing on the effect of varying both the fiber length $(25,35,45$ and $55 \mathrm{~mm})$ and the relative volume fraction between glass and ramie fibers. In all experiments the overall fiber loading was kept constant (21 vol.\%).

\section{Experimental Procedures}

\subsection{Materials}

Ramie roving was purchased from Sisalsul Fibras Naturais (São Paulo, SP, Brazil), and glass fiber roving

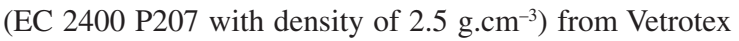
(Capivari, SP, Brazil). Modified unsaturated polyester resin UCEFLEX UC 5530-M was supplied by Elekeiroz S.A (Varzea Paulista, SP, Brazil). Mold-releasing agent poly(vinyl alcohol) (PVA), curing agent methyl ethyl ketone peroxide in diisobutyl phthalate (BUTANOX LPT) and the promoter dimethylaniline (DMA) were purchased from Disfibra (Caxias do Sul, RS, Brazil).

\subsection{Preparation of fiber}

In a previous study, it was defined the range of the fiber lengths: it was impracticable to prepare the mats with less than $25 \mathrm{~mm}$ fibers lengths by the difficulty to chop and separate the fibers; in lengths exceeding $55 \mathrm{~mm}$ it was evidenced a curvature of the fiber (bending) in the mat manufacturing. As already reported in the literature ${ }^{15}$, this fact causes a decrease in mechanical properties of the composite. Then, glass and ramie fibers were chopped in different lengths: 25, 35, 45 and $55 \mathrm{~mm}$. The natural fiber was immersed in distilled water for 10 minutes, then twisted and washed (with distilled water at $20-25^{\circ} \mathrm{C}$ ) for 50 minutes. It was then oven-dried at $105{ }^{\circ} \mathrm{C}$ with air circulation for 60 minutes. Finally, the ramie fibers were manually selected to eliminate wastes. The method was adapted by Ornaghi et al. ${ }^{16}$ studies.

\subsection{Mat manufacturing}

The glass and ramie fibers were mixed and manually arranged in a pre-mold of same shape of the mold in order to produce a hybrid mat. The overall fiber loading was kept constant (21 vol.\%). This value was defined in accordance with the best results obtained in previous studies ${ }^{17}$ in the same mold. The glass fiber loading was varied from 0 to 75 vol. \%. It was not possible to molding composites with $100 \%$ of glass fiber in this method due to the fiber dragging through the resin flow during the molding process. The relative volume fraction between glass fiber (GF) and washed ramie fibers (RF) is shown in Table 1.

For example, the $45 \mathrm{~mm}$ fiber length, $25 \%$ glass fiber and $75 \%$ of ramie fiber loading composite was designated by $(45 / 25: 75)$.

\subsection{Preparation of composites}

Before molding, the mat was pressed under the following conditions: 10 minutes, $49 \mathrm{kN}$ and $80{ }^{\circ} \mathrm{C}$. Also before molding a mold-releasing agent (PVA) was applied to the mold. The polyester resin used was manually mixed (for approximately 1 minute) with $0.5 \mathrm{wt}$. (\%) of Butanox LPT and 0.1 wt. (\%) of DMA, respectively. The process parameters used in the resin transfer molding (RTM) were: mold temperature between 20 and $25^{\circ} \mathrm{C}$, positive pressure of 0.5 bar. The resin preparation and process parameters were defined in a previous experiment, considering the resin gel time. The curing was carried out in situ at a temperature of $25^{\circ} \mathrm{C}$ for 24 hours, followed by first post-curing at $80{ }^{\circ} \mathrm{C}$ for 6 hours and second post-curing at $120^{\circ} \mathrm{C}$ for 2 hours ${ }^{18,19}$.

\subsection{Characterization}

The fibers were investigated by Fourier Transform Infrared Spectroscopy (FTIR - Nicolet IS10 - Termo Scientific), using the Attenuated Total Reflectance (ATR) technique. Thermogravimetry (TGA - Shimadzu TGA-50) was performed in the temperature range from 25 to $900{ }^{\circ} \mathrm{C}$ at a heating rate of $10{ }^{\circ} \mathrm{C} \cdot \mathrm{min}^{-1}$. Three samples were taken for FTIR and TGA analyses. The glass fiber density was confirmed $\left(2.53 \pm 0.03 \mathrm{~g} . \mathrm{cm}^{-3}\right)$ using the pycnometry analysis, with water (solvent). The ramie fiber density was determined using a helium Picnometer (MVP-1 Quantachrome). Four analyses were taken and the average density value was reported.

The fiber diameter and surface cross-section of the hybrid composite (cryogenically fractured samples) were carried out using a Scanning Electron Microscope (SEM - JEOL JSM-6060). The average diameter of about 30 samples was determined. All specimens were sputtered with a layer of gold prior to SEM observations. Samples were

Table 1. Composition of the mat (\% vol.)

\begin{tabular}{ccc}
\hline (GF:RF)* & $\begin{array}{c}\text { Glass fiber content } \\
(\boldsymbol{\%})\end{array}$ & $\begin{array}{c}\text { Ramie fiber content } \\
(\boldsymbol{\%})\end{array}$ \\
\hline$(0: 100)$ & 0 & 100 \\
$(25: 75)$ & 25 & 75 \\
$(50: 50)$ & 50 & 50 \\
$(75: 25)$ & 75 & 25 \\
\hline
\end{tabular}

*GF = Glass Fiber; RF = Washed Ramie Fiber. 
oven-dried at $70{ }^{\circ} \mathrm{C}$ with air circulation for 24 hours. After that, the fibers and composites were mounted on aluminum holders using double-sided electrically conducting carbon adhesive tabs prior to the analysis.

Unnotched Izod impact test was performed using a CEAST impact machine in accordance with ASTM D256-04 ${ }^{[20]}$. Specimens of $63.5 \times 12.7 \times 4 \mathrm{~mm}$ were prepared, and the maximum energy of the hammer used for hybrid composites, natural fiber composites and resin were 7.5, 2 and $1 \mathrm{~J}$, respectively. An average value from ten replicates of each sample was taken. The flexural tests (three point bending configuration) were performed in the universal testing machine EMIC DL-3000, in accordance with the D7264M-0 $7^{[21]}$ standard. Specimens of $128 \times 13 \times 4$ were prepared, and the test was conducted using a load cell of $2 \mathrm{kN}$ at $1.8 \mathrm{~mm} / \mathrm{min}$ rate of loading. Seven specimens were tested in each case and the average values were reported. All tests were conducted at a temperature of $23 \pm 2{ }^{\circ} \mathrm{C}$ and $50 \pm 5 \%$ relative humidity.

\section{Results and Discussion}

\subsection{Fiber characterization}

The average density obtained for washed ramie fibers was $1.49 \pm 0.04 \mathrm{~g} . \mathrm{cm}^{-3}$, the values being comparable to those of the literature $\left(1.50 \mathrm{~g} . \mathrm{cm}^{-3}\right)^{[13]}$. The average diameter for in natura fibers was $77.7 \pm 19.8 \mathrm{~mm}$, and for washed fibers was $69.5 \pm 19.6 \mathrm{~mm}$. The fibrils are a constituent of the fiber, with an average diameter of $12 \pm 4 \mathrm{~mm}$. Thus, the ramie fibers presented values close to the range found in the literature: 18 to $80 \mathrm{~mm}^{[13]}$.

The absorption bands for characteristic chemical groups of the lignocellulosic fibers composition (cellulose, hemicellulose and lignin) can be observed in Figure 1. The spectra revealed a broad and intense peak at $3340 \mathrm{~cm}^{-1}$, characteristic of the hydroxyl groups present in the cellulose, water and lignin structures ${ }^{22-23}$. The peaks at 2920 and $2850 \mathrm{~cm}^{-1}$ are characteristic bands of the C-H stretching vibration present in the cellulose and hemicellulose components. The characteristic $1730 \mathrm{~cm}^{-1}$ band corresponds to the carbonyl $(\mathrm{C}=\mathrm{O})$ stretching vibration in hemicellulose $\mathrm{e}^{9,23-24}$.

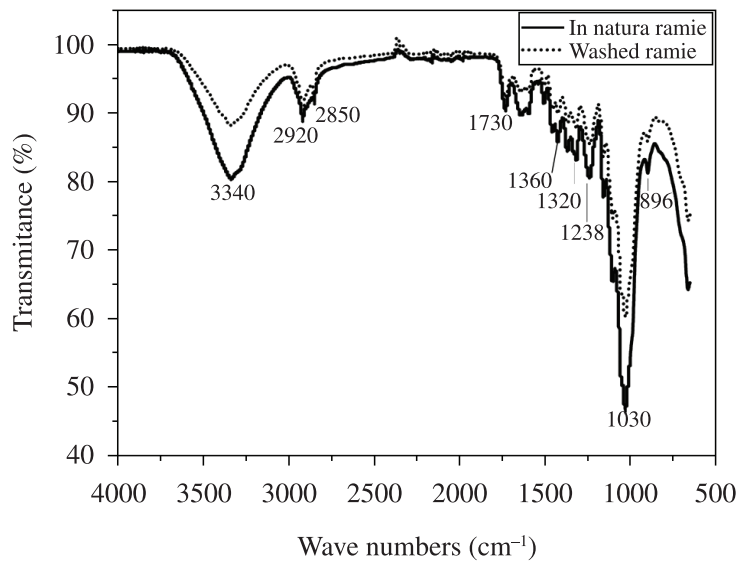

Figure 1. ATR-FTIR spectra of in natura fiber (NF) and washed fiber (WF).
Between 1320 and $1360 \mathrm{~cm}^{-1}$ the absorption peak refers to the bending vibration of $\mathrm{C}-\mathrm{H}$ and $\mathrm{C}-\mathrm{O}$ groups of the aromatic rings in polysaccharides ${ }^{9}$. The band at $1238 \mathrm{~cm}^{-1}$ is relative to the $(\mathrm{C}-\mathrm{O})$ vibration of esters, ethers and phenolic groups attributed to the presence of wax on the fiber surface ${ }^{23}$. The absorption peak at $1030 \mathrm{~cm}^{-1}$ is related to the $(\mathrm{CO})$ and $(\mathrm{O}-\mathrm{H})$ stretching vibrations which belong to the polysaccharide in cellulose. Finally, the peak observed at $896 \mathrm{~cm}^{-1}$ is attributed to the presence of b-glycosidic linkages between the monosaccharides ${ }^{9}$.

Data obtained by FTIR analysis show differences in the intensities between in natura and washed ramie fiber in two main absorption cellulose bands (3340 and $\left.1030 \mathrm{~cm}^{-1}\right)$. In the spectrum of the in natura fiber, these bands are more accentuated, and it can be an indicative of a larger exposition of cellulose and water on the fiber surface. It is known that more than $70 \mathrm{wt}$. (\%) of the fiber structure is composed of cellulose and 7.5-17 wt. (\%) of moisture content ${ }^{9}$. Then, it is possible that part of water and cellulose present in the fiber surface could be removed by the method of fiber's preparation (washing, drying and selection processes).

The thermogravimetric curves of the in natura fiber (NF) and washed fiber (WF) can be seen in Figure 2.

The thermogravimetric curve of ramie fiber shows three weight loss steps. The initial weight loss observed between 40 and $110{ }^{\circ} \mathrm{C}$ is attributed to the vaporization of the water from the fibers. The second weight loss with the maximum decomposition rates in $289^{\circ} \mathrm{C}(\mathrm{NF})$ and $297{ }^{\circ} \mathrm{C}$ (WF), is associated to the thermal depolymerisation of hemicellulose, pectin and the cleavage of glycosidic linkages of cellulose, while the third weight loss $\left(368.15^{\circ} \mathrm{C}\right.$ for $\mathrm{NF}$ and $372.8^{\circ} \mathrm{C}$ for WF) corresponds to the degradation of $\alpha$-cellulose present in the fiber. The decomposition of lignin occurs slowly within the whole temperature range, owing to its complex structure?

The ramie fiber washing process promoted an increase in the thermal stability, shifting the degradation peaks to higher temperatures $\left(289\right.$ to $297^{\circ} \mathrm{C}$ and 368.15 to $372.8^{\circ} \mathrm{C}$ ). It was also observed a slight difference in the curves behavior below $220{ }^{\circ} \mathrm{C}$, probably due to the more accentuated presence of water, wax and residues in the in natura fibers. The wasting removal during the washing process can also explained by differences in the mass residues that remains at $800{ }^{\circ} \mathrm{C}$ ( $16 \%$ for natural fibers and $10.5 \%$ for washed fibers). In this case, it should be responsible for the increasing of the thermal stability. From an earlier study realized by Spinacé et al. ${ }^{9}$ it is known that the water washed curaua fibers presented a $10^{\circ} \mathrm{C}$ increase in the temperature of the maximum rate of the cellulose degradation process.

\subsection{Influence of fiber length and hybridization}

The analyses of the results obtained were realized by comparison of the experimental data. Flexural properties of the composites are shown in Figure 3. All composites showed higher flexural strength when compared to the neat resin. The flexural strength of neat resin is found to $36.4 \pm 5 \mathrm{MPa}$. By the incorporation of ramie fiber (0:100 - $45 \mathrm{~mm}$ fibers length), the flexural strength increases by about $57 \%$. It was also observed an increase in the flexural strength as the relative glass fiber volume fraction increases. Data from 


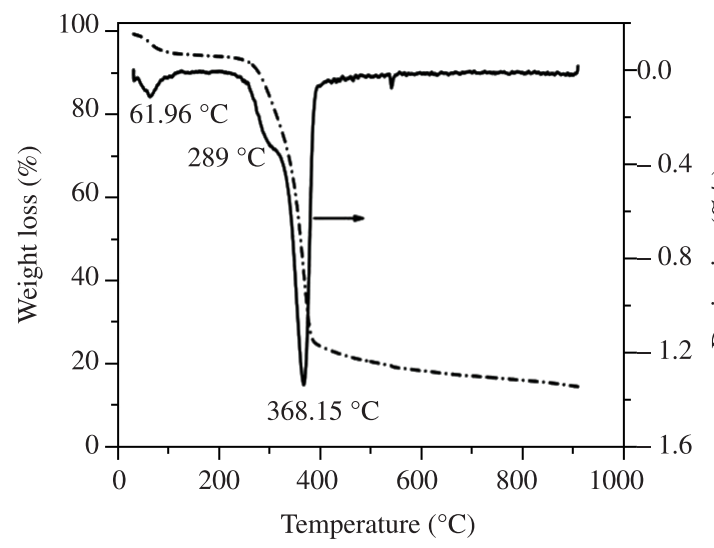

(a)

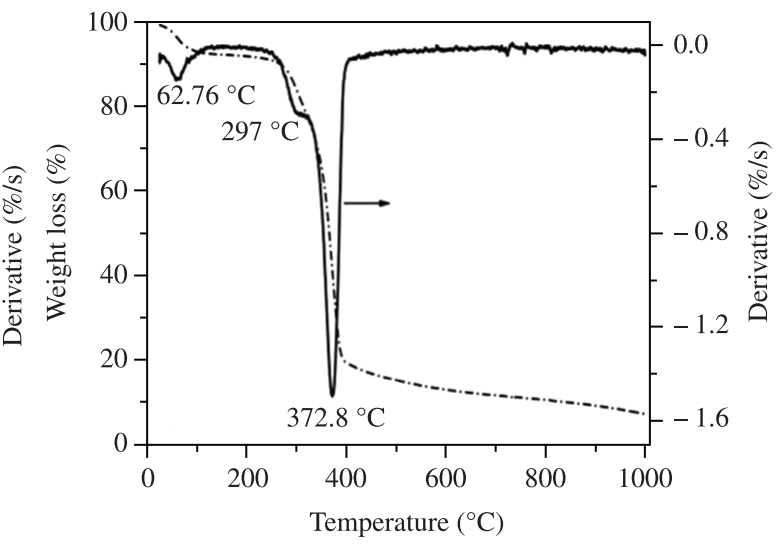

(b)

Figure 2. Thermogravimetric curves of (a) in natura fiber and (b) washed fiber.

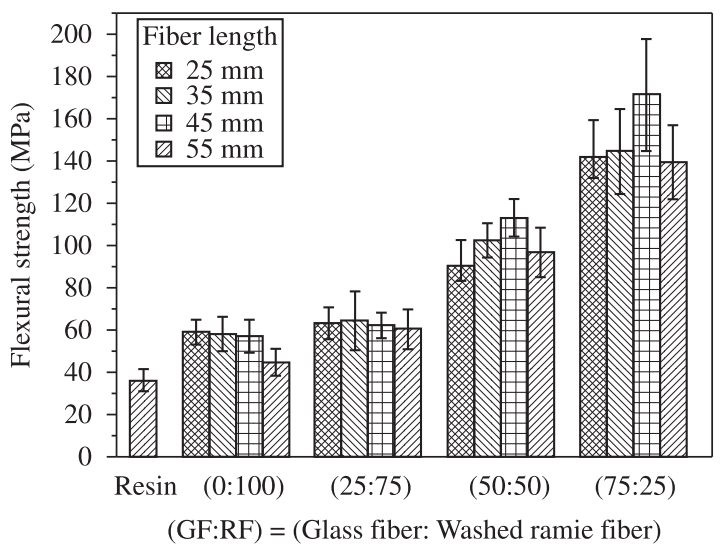

Figure 3. Effect of fiber length on the flexural strength in different glass and ramie fraction (standard deviations are represented by bars).

literature $^{13}$ indicates the tensile strength (2000-3500 MPa and $500 \mathrm{MPa}$ ) and the Young's modulus (70 and $44 \mathrm{GPa}$ ) for E-glass and ramie fibers, respectively. Thus, this increasing is due to the stronger and stiffer characteristics of the glass fiber in comparison with the ramie fiber ${ }^{25}$ and also to the better adhesion of the synthetic fiber to the polyester resin in comparison with ramie fiber, with consequently higher degree of stress transfer to the former fibers upon loading ${ }^{16}$. It is important to mention that, in a three-point flexure test, failure occurs due to bending and shear failure, so by raising the glass fiber content the flexural strength will be improved due to increased shear resistance between fiber and matrix ${ }^{26}$.

There was no significant influence of the fiber length on the flexural strength measurements of composites containing (0:100) and (25:75) fiber loading. The $45 \mathrm{~mm}$ fiber length composites showed better performance than other fiber lengths studied (50:50 and 75:25 fiber loading). The lower values found for the $55 \mathrm{~mm}$ fiber length composites may be due to the difficulty of adequately distributing and homogenizing the fibers in the mold ${ }^{15}$.

Figure 4 shows the effects of different glass and ramie fiber ratios on the impact strength. All composites showed remarkably higher impact strength when compared

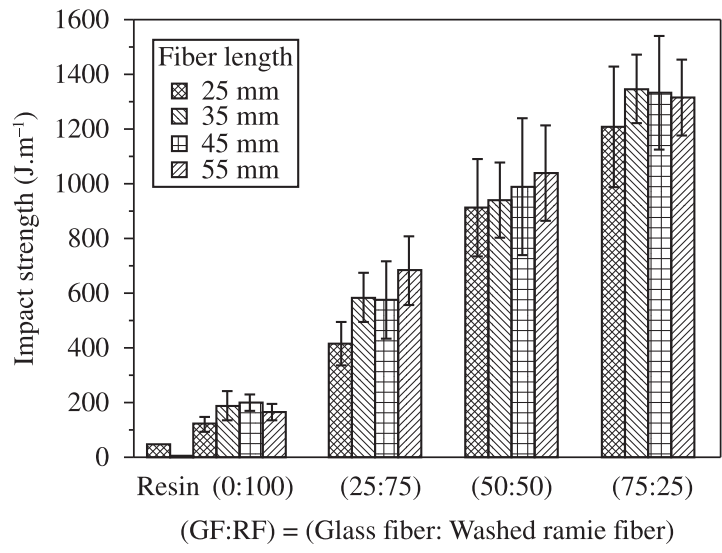

Figure 4. Effect of fiber length on the impact strength in different glass and ramie fraction (standard deviations are represented by bars).

to the neat resin. The impact strength of neat resin is found $48.6 \pm 6 \mathrm{MPa}$. By the incorporation of ramie fiber (0:100 - $45 \mathrm{~mm}$ fibers length), the impact strength increases by approximately $309 \%$. The important role of the fibers in the impact resistance can be explained on the basis that the fibers interact with the crack formation in the matrix acting as a stress transfer agent ${ }^{26}$. In a composite, the load is transferred through shear; and when the shear force exceeds the fiber matrix interaction force, the fiber matrix debonding takes place. Fiber fracture will be predominating when the stress level exceeds the fiber stress, and then the fractured fibers are pulled out from the matrix ${ }^{27}$.

Moreover, it can be noted that the impact strength increased as a result of the glass fiber incorporation. The glass fiber enables better adhesion to the polyester resin than the ramie fiber, and this increase can be attributed to the better energy dissipation at the glass-matrix interface in order to detach the fibers from the matrix ${ }^{16-17}$. The impact strength of the (45/50:50) composite increased $80.2 \%$ in comparison with the $(45 / 25: 75)$ composite. For the (45/75:25) composite, there was a relative increasing of $142.6 \%$ in comparison to the (45/25:75) composite. 


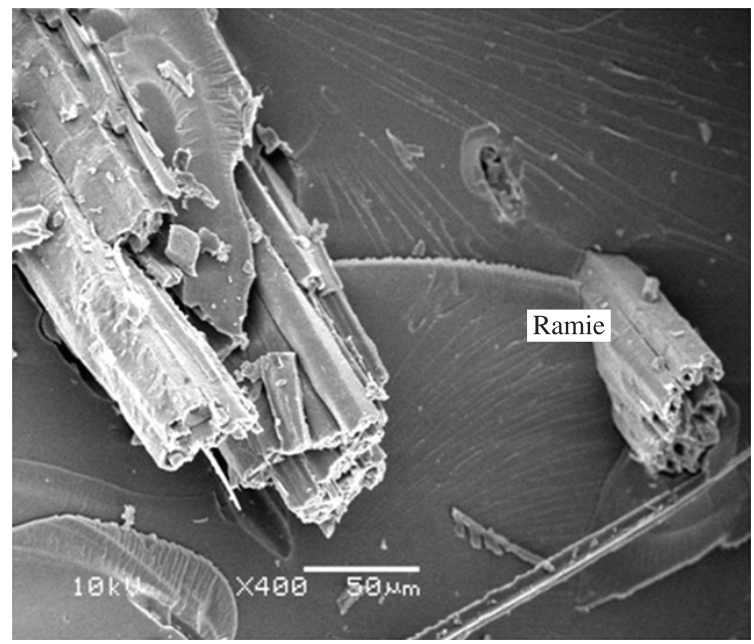

(a)

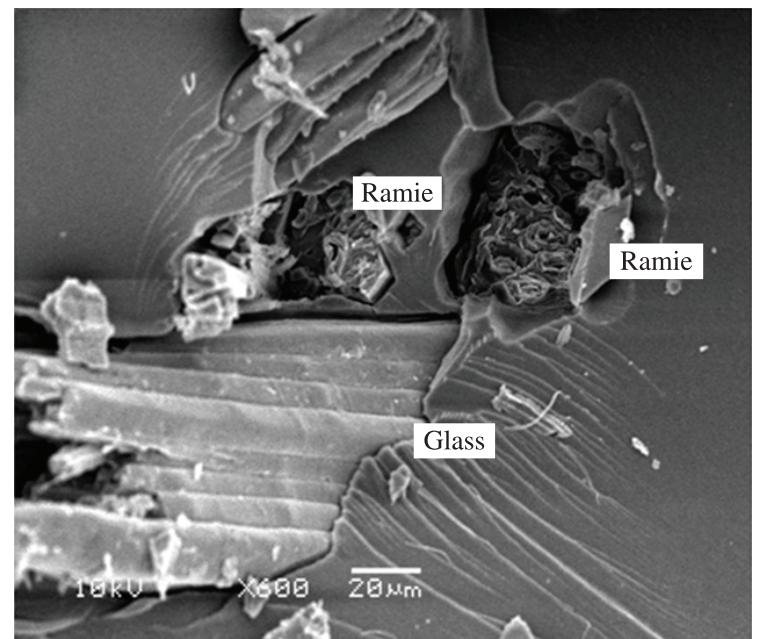

(b)

Figure 5. SEM micrographs of composites with (a) $45 \mathrm{~mm}$ and (b) $55 \mathrm{~mm}$ of fiber length.

Finally, it is expect that increasing the fiber length the impact strength increases due to the higher energy dissipation along the fiber length. Consequently, higher energy absorption is achieved ${ }^{28}$. As shown in Figure 3, considering the standard deviation, this tendency did not show a significant influence for all the glass/ramie fractions.

The influence of fiber length as well as the efficiency of the bonding between fiber and matrix is important to ensure high strength and stiffness to the composites. Therefore, there is a critical length that must be exceeded for the fiber to fracture without pullout. For values below the critical length, the failure usually occurs at the interface by fiber debonding ${ }^{29}$. Angelini et al. ${ }^{30}$ studied ramie fiber and obtained a critical length $(l c)$ of $0.47 \mathrm{~mm}$. Thus, the range of lengths studied in this work exceeds the critical length found in the literature.

Figure 5 shows the fracture surface of 45 and $55 \mathrm{~mm}$ fiber length hybrid composites. The presence of short fractured fibers projecting out of the matrix can be indicative that, in general, there was no pullout failure.

Therefore, a good adhesion between fiber-matrix can be obtained for ramie fiber just by removing the fiber impurities with distilled water.

\section{Conclusion}

Washed ramie fibers may be considered an alternative for the manufacturing of the polymeric hybrid composites.
FTIR analysis shows a slight difference between in natura and washed fibers, even as thermal analysis showed an increase in the thermal stability, shifting the degradation peaks to higher temperatures. The $45 \mathrm{~mm}$ fiber length composites showed better performance in flexural strength as compared with those of 25, 35 and $55 \mathrm{~mm}$ fiber length, although this difference is not significant for lower glass fiber volume fractions (0:100) and (25:75). The drawbacks encountered in the $55 \mathrm{~mm}$ length fiber processing lead out to the low values assessed for these composites. Furthermore, the ramie fiber promoted higher mechanical properties in the composites studied. With hybridization, an increasing in the relative volume fraction of glass fiber until an upper limit of $75 \%$ was observed as well higher flexural and impact properties. So, ramie fiber should be considered an alternative to substitute partially glass fibers in polymer composites.

\section{Acknowledgements}

The authors wish to thank CNPq and CAPES for the financial support, LPOL for providing the experimental testing and particularly Elekeiroz S.A for providing the polyester resin. Authors are also indebted to the PGEPROTEC (UCS) and PPGEM (UFRGS) postgraduate programs.

\section{References}

1. Paul SA, Joseph K, Mathew GDG, Pothen LA and Thomas S. Influence of polarity parameters on the mechanical properties of composites from polypropylene fiber and short banana fiber. Composites: Part A. 2010; 41:1380-1387. http://dx.doi. org/10.1016/j.compositesa.2010.04.015

2. Margemi FM, Monteiro SN, Bravo Neto J, Rodriguez RJS and Soares BG. The dynamic-mechanical behavior of epoxy matrix composites reinforced with ramie fibers. Revista Matéria. 2010; 15:164-171.

3. Sgriccia N, Hawley MC and Misra M. Characterization of natural fiber surfaces and natural fiber composites. Composites: Part A. 2008; 39:1632-1637. http://dx.doi.org/10.1016/j. compositesa.2008.07.007

4. Santos RS, De Souza AA and De Paoli MA. Cardanolformaldehyde thermoset composites reinforced with buriti fibers: Preparation and characterization. Composites: Part A. 2010; 41:1123-1129. 
5. Shih YF. A study of the fiber obtained from the water bamboo husks. Bioresource Technology. 2007; 98:819-828. PMid:16759852. http://dx.doi.org/10.1016/j. biortech.2006.03.025

6. Sreekumar PA, Joseph K, Unnikrishanan G and Thomas S. A comparative study on mechanical properties of sisal-leaf fibrereinforced polyester composites prepared by resin transfer and compression moulding techniques. Composites Science and Technology. 2007; 67:453-461. http://dx.doi.org/10.1016/j. compscitech.2006.08.025

7. John MJ and Thomas S. Biofibres and biocomposites. Carbohydrate Polymers. 2008; 71:343-364. http://dx.doi. org/10.1016/j.carbpol.2007.05.040

8. Leão MA. Fibras de Lucuri: um reforço alternativo de compósitos poliméricos. [Dissertação]. Natal: Universidade Federal do Rio Grande do Norte; 2008.

9. Rosa IM, Kenny JM, Maniruzzaman M, Moniruzzaman M, Monti M, Puglia D et al. Effect of chemical treatments on the mechanical and thermal behaviour of okra (Abelmoschus esculentus) fibres. Composites Science and Technology. 2010; 71:246-254. http://dx.doi.org/10.1016/j. compscitech.2010.11.023

10. Rassmann S, Reid RG and Paskaramoorthy R. Effects of processing conditions on the mechanical and water absorption properties of resin transfer moulded kenaf fibre reinforced polyester composite laminates. Composites: Part A. 2010; 41:1612-1619. http://dx.doi.org/10.1016/j. compositesa.2010.07.009

11. Spinacé MAS, Lambert CS, Fermoselli KG and De Paoli MA. Characterization of lignocellulosic curaua fibres. Carbohydrate Polymers. 2009; 77:47-53. http://dx.doi.org/10.1016/j. carbpol.2008.12.005

12. Vieira CAB, Susini SB, Freire E, Amico SC and Zattera AJ. Characterization of hybrid composites produced with mats made using different methods. Materials research. 2009; 12, n. 4:1-7. http://dx.doi.org/10.1590/S1516-14392009000400011

13. Jawaid M and Abdul Khalil HPS. Cellulosic/synthetic fibre reinforced polymer hybrid composites: A review. Carbohydrate Polymers. 2011; 86:1-18. http://dx.doi.org/10.1016/j. carbpol.2011.04.043

14. Paiva Júnior CZ, De Carvalho LH, Fonseca VM, Monteiro SN and D'Almeida JRM. Analysis of the tensile strength of polyester/hybrid ramie-cotton fabric composites. Polymer Testing. 2004; 23:131-135. http://dx.doi.org/10.1016/ S0142-9418(03)00071-0

15. Kuruvilla J, Medeiros ES and Carvalho LH. Compósitos de Matriz Poliéster Reforçados por Fibras Curtas de Sisal. Polímeros. 1999; 9, n.4:136-141. http://dx.doi.org/10.1590/ S0104-14281999000400023

16. Ornaghi Junior, HL, Silva HSP, Zattera AJ and Amico SC. Hybridization effect on the mechanical and dynamic mechanical properties of curaua composites. Materials Science and Engineering. 2011; 528:7285-7289. http://dx.doi. org/10.1016/j.msea.2011.05.078

17. Ornaghi Junior HL, Bolner AS, Fiorio R, Zattera AJ and Amico SC. Mechanical and Dynamic Mechanical Analysis of Hybrid Composites Molded by Resin Transfer Molding. Journal of Applied Polymer Science. 2010; 118:887-896.
18. Bureau E, Chebli K, Cabot C, Saiter JM, Dreux F, Marais $\mathrm{S}$ et al. Fragility of unsaturated polyester resins cured with styrene: influence of the styrene concentration. European Polymer Journal. 2001; 37:2169-2176. http://dx.doi. org/10.1016/S0014-3057(01)00114-8

19. Delahaye N, Marais S, Saiter M and Metayer M. Characterization of Unsaturated Polyester Resin Cured with Styrene. Journal of Applied Polymer Science. 1998; 67, 695-703. http://dx.doi. org/10.1002/(SICI) 1097-4628(19980124)67:4\%3C695::AID -APP12\%3E3.0.CO;2-3

20. American Society for Testing and Materials - ASTM. ASTM D256: Standard test methods for determining the Izod pendulum impact resistance of plastics. Philadelphia: ASTM; 2010.

21. American Society for Testing and Materials - ASTM. ASTM D7264M: Standard test methods for flexural properties of polymer matrix composite materials. Pennsylvania: ASTM; 2007.

22. Tomczak F, Satyanarayana KG and Sydenstricker THD. Studies on lignocellulosic fibers of Brazil: Part III - Morphology and properties of Brazilian curauá fibers. Composites: Part A. 2007; 38:2227-2236. http://dx.doi.org/10.1016/j. compositesa.2007.06.005

23. Brígida AIS, Calado VMA, Gonçalves LRB and Coelho MAZ. Effect of chemical treatments on properties of green coconut fiber. Carbohydrate Polymers. 2010; 79:832-838. http://dx.doi. org/10.1016/j.carbpol.2009.10.005

24. Reddy KO, Maheswari CU, Reddy DJP and Rajulu AV. Thermal properties of Napier grass fibers. Materials Letters. 2009; 63:2390-2392. http://dx.doi.org/10.1016/j. matlet.2009.08.035

25. Jarukumjorn K and Suppakarn N. Effect of glass fiber hybridization on properties of sisal fiber-polypropylene composites. Composites Part B: Engineering. 2009; 40:623-627. http://dx.doi.org/10.1016/j.compositesb.2009.04.007

26. Mishra S, Mohanty AK, Drzal LT, Misra M, Parija S, Nayak SK et al. Studies on mechanical performance of biofibre/ glass reinforced polyester hybrid composites. Composites Science and Technology. 2003; 63:1377-1385. http://dx.doi. org/10.1016/S0266-3538(03)00084-8

27. Velmurugan R and Manikandan V. Mechanical properties of palmyra/glass fiber hybrid composites. Composites: Part A. 2007; 38:2216-2226. http://dx.doi.org/10.1016/j. compositesa.2007.06.006

28. Angrizani CC, Vieira CAB, Zattera AJ, Freire E, Santana RMC and Amico SC. In: Anais do 17th Congresso Brasileiro de Ciência e Engenharia de Materiais - CBECIMAT; 2006; Foz do Iguaçu. São Paulo; 2006.

29. Monteiro SN and Almeida JRM. Ensaios de Pullout em Fibras Lignocelulósicas - Uma Metodologia de Análise. Revista Matéria. 2006; 11(3):189-196.

30. Angelini LG, Lazzeri A, Levita G, Fontanelli D and Bozzi C. Ramie (Boehmeria nivea (L.) Gaud.) and Spanish Broom (Spartium junceum L.) fibres for composite materials: agronomical aspects, morphology and mechanical properties. Industrial Crops and Products. 2000; 11:145-161. http://dx.doi. org/10.1016/S0926-6690(99)00059-X 